\title{
The potential combination of smart and active packaging in one packaging system in improving and maintaining the quality of fish
}

Dewi Sisilia Yolanda*, Andi Dirpan, Andi Nur Faidah Rahman, Muspirah Djalal and Serli Hatul Hidayat

Department of Agricultural Technology, Hasanuddin University, Makassar, Indonesia

\begin{abstract}
A long shelf life fresh food with a little or no preservatives is being a hot issue these days. In response to the issue, various forms of packaging technology innovation were created, such as smart packaging and active packaging. The packaging innovation in this study was designed to provide quality assurance of packaged food to consumers, especially for Tuna fillets. The purpose of this study was to determine the color change profile of smart indicator labels, to determine the effectiveness of active paper (addition of garlic extract $0 \%, 5 \%, 10 \%$, and $15 \%$ ) when applied to Tuna fillets stored at room temperature $\left(28 \pm 2^{\circ} \mathrm{C}\right)$, and to find out the level of correlation between smart indicator labels and active paper against various parameters of Tuna fillet rot test like total volatile base nitrogen (TVBN), total bacteria (TPC), and $\mathrm{pH}$. All these parameters were tested at room temperature every 2 hours until 12 hours with two replications. The results obtained showed that the smart label indicator changed color from dark red to yellow when the fillet was decomposed. Active paper with the addition of garlic extract concentration of $15 \%$ had the best effectiveness in minimizing the occurrence of any deterioration in the Tuna fillets during storage, which was then followed by a concentration of $10 \%, 5 \%$, and $0 \%$. The level of correlation between the value of the smart indicator color analysis and the effectiveness of the active paper on various fish rot test parameters showed a positive correlation which showed the same tendency pattern in the detection rate of the decomposition of Tuna fillet.
\end{abstract}

Article History

Received September 06,

2020

Accepted December 29,

2020

\section{Keyword}

garlic extract, smart packaging, active packaging, tuna fillets.

\section{Introduction}

Indonesia has a huge potential in the fisheries sector. As reported by Information System for Dissemination of Data and Statistics on Marine and Fisheries (2016) that in the year of 2014-2016, the projected production of national marine waters had increased from 6.037.654.00 to 6.351.480.00 tons. Likewise, fish consumption in Indonesia in 2014-2016 increased from 38.14 to 43.88 (kg/year) (1). The high number of fish production and consumption in Indonesia is directly proportional to the fish damage that occurs. It is because fish has a high nutritional value, in particular, free amino acids, which are potentially used by microorganisms for growth and development (2).

Another problem that often occurs is that the packaged food which is not suitable for consumption sometimes is still being traded which can harm the consumers from an economics and health perspective. Therefore, it is necessary to enhance the packaging 
technology to ensure the quality of fish, it is including the application of smart and active packaging.

Lately, the use of packaging based on Early Warning Indicator (smart) and active packaging has become a hot issue in various countries, especially in developed countries. That is in response to the needs of the food industry and consumers who increasingly prioritize fresh food and have a long shelf life with little or no preservatives. In contrast to the concept of conventional packaging, which has the principle of protecting food without interaction with packaging, active packaging and smart packaging actually utilizes the interaction between food ingredients or their environment with the packaging. Smart packaging is designed to provide actual information about the level of freshness and safety of food products, including fishery products that are packaged during storage, transportation, and distribution.

Some studies were still mostly limited to the application of just one packaging element, such as smart packaging or active packaging. Therefore, in this research, smart and active packaging is combined in one packaging system that aimed to achieve the optimization of the function of packaging technology that was specifically applied to Tuna fillets. This study aimed to determine the color change profile of smart indicator labels when applied to Tuna fillets, determined the effectiveness of active paper and determined the level of correlation between the values of intelligent indicator color analysis against various parameters of Tuna fillet decay test.

\section{Materials and Methods}

\subsection{Materials}

The tools used in this research were the Petri dishes, blenders, beakers, test tubes, vortices, knive, digital microscope (models: digital microscope 5-500 x), Conway cups, pH meter, autoclaves, analytical scale, hairdryer (Philips), laminar airflow, hot plate, evaporator, Oven, digital peniter, colorimeter, refrigerator, incubator and tally counter. While the materials used in this study were: Albakora Tuna fish, bromothymol blue (BTB), methyl red (MR), glacial acetic acid 96\%, ethanol 96\%, $\mathrm{HCl} 0.02 \mathrm{~N}, \mathrm{H}_{3} \mathrm{BO}_{3} 2 \%, \mathrm{~K}_{2} \mathrm{CO}_{3}$ saturated, TCA 7\%, nutrient agar, agar powder, Whatman paper number 1, tapioca starch, chitosan powder, garlic, tween 80 /polysorbate 80 , aquadest, styrofoam, and LDPE plastic.

\subsection{Research Procedure}

\subsubsection{Making Indicator Solutions (3)}

Indicator solution combination of methyl red and bromothymol blue (BTB) was made of $1 \%(\mathrm{w} / \mathrm{v})$ each, which was dissolved in 95\% ethanol. Then the MR + BTB indicator solution (1: 1) was adjusted to $\mathrm{pH} 2.55$ using a glacial acetic acid solution.

\subsubsection{Smart Indicator Label Procedure $(3,4)$}

The number 1 sheet of Whatman paper was cut into $2 \times 4 \mathrm{~cm}^{2}$ size and then soaked in $10 \mathrm{ml}$ of the MR + BTB combination indicator solution (1: 1) at $\mathrm{pH} 2.55$ and room temperature $\left(28 \pm 2^{\circ} \mathrm{C}\right)$ for 12 hours. After that, the smart indicator label was dried with an electric dryer. 


\subsubsection{Garlic Extract Procedure (5,)}

The manufacture of garlic extract used the maceration method. The procedure for making garlic extract began with the process of sorting garlic, then stripping the skin. After that, $50 \mathrm{~g}$ of garlic was blended until smooth, then put into a jar containing $250 \mathrm{ml}$ of $96 \%$ alcohol with a ratio (1: 5) for $3 \times 24$ hours. Stirring was done 12 times for 15 minutes. Furthermore, filtering was done to separate the garlic pulp from the filtrate. The filtrate was then evaporated at $45^{\circ} \mathrm{C}$ until a thick reddish-yellow garlic extract was obtained.

\subsubsection{Active Paper Procedure (7)}

Filter paper cut $\left(2 \times 2 \mathrm{~cm}^{2}\right) 10 \mathrm{~g}$ soaked in $170 \mathrm{ml}$ of distilled water with a ratio of 1:17 for 24 hours. Soaking paper pieces added with $170 \mathrm{ml}$ of distilled water and blended for 5 minutes until it became pulp. Next, the paper pulp was squeezed until the water run out. After that, $6 \mathrm{~g}$ or $60 \%(\mathrm{w} / \mathrm{w})$ of tapioca starch was dissolved in $30 \mathrm{ml}$ of distilled water in a ratio of 1: 5 and mixed with pulp and then homogenized. $0.6 \mathrm{~g}$ or $6 \%(\mathrm{w} / \mathrm{w})$ of chitosan powder was added to the beaker containing $30 \mathrm{ml}$ of $1 \%$ acetic acid by comparison 1:50. The solution was then mixed with pulp and then blended for 5 minutes. After that, the addition of garlic extract with a concentration of $0 \%, 5 \%, 10 \%$, and $15 \%(\mathrm{w} / \mathrm{v})$ and each tween $80 /$ polysorbate 80 was added by $6 \%(\mathrm{w} / \mathrm{v}$ ) into the paper mixture. The finished paper dough was then printed manually on an oven chamfer with a size of $8 \times 15 \mathrm{~cm}^{2}$ according to the size of the styrofoam. After that, the sheet of wet paper was dried using an oven at $40^{\circ} \mathrm{C}$ for \pm 15 hours.

\subsubsection{Application of Smart and Active Packaging in Tuna Fish Fillets}

Fresh Albacora Tuna species were obtained from the Fish Auction site in Maros Regency. The Tuna was then directly placed in a cool box with a size of $38 \times 29 \times 30 \mathrm{~cm}^{3}$ which contained ice in comparison 1:3. Subsequently, the samples were immediately transported to the Laboratory and sterile prepared until a $100 \mathrm{~g}$ Tuna/fish fillet was obtained. The fish fillets were then placed in styrofoam coated with active paper measuring $15 \times 8 \mathrm{~cm}^{2}$. Furthermore, the indicator label was placed inside the package by sticking the label on the LDPE plastic wrap as a cover. After that, Tuna fillets were kept at room temperature for 12 hours. The following were smart indicator label designs and smart and active packaging designs.

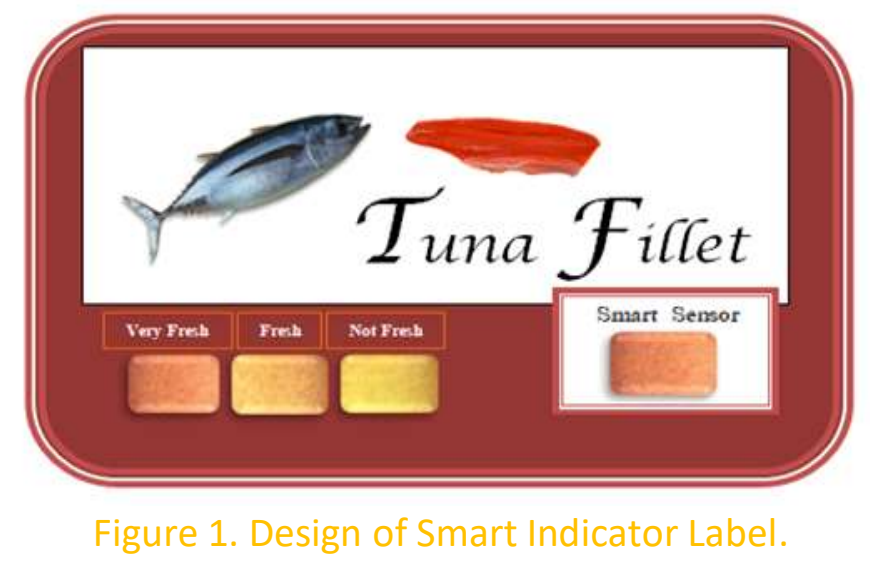




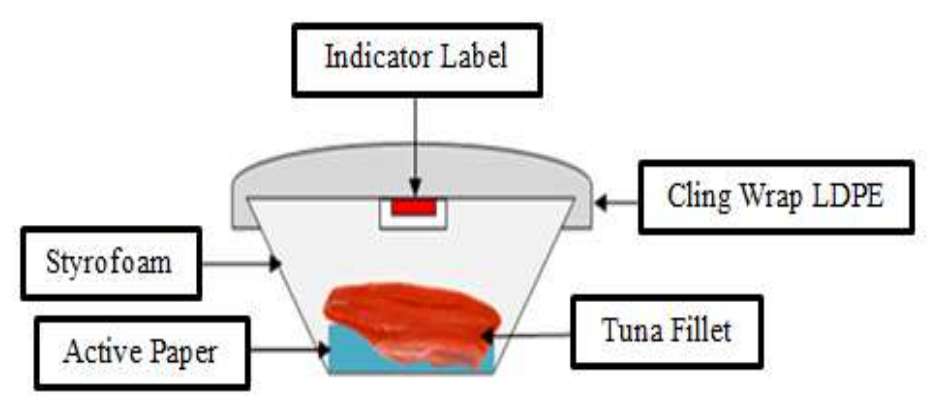

Figure 2. Design of Smart and Active Packaging.

\subsection{Research Design}

The design in this study was the addition of garlic extract to active paper with different concentrations.

A0: Control (0\%)

A1: Addition of garlic extract $5 \%$,

A2: Addition of garlic extract $10 \%$,

A3: Addition of garlic extract $15 \%$.

Packed Tuna fillet was stored at room temperature $\left(28 \pm 2^{\circ} \mathrm{C}\right)$ for 12 hours.

\subsection{Observation Parameters}

Observation parameters and data measurements were carried out every 2 hours for 12 hours at room temperature. Observation parameters could be in the form of measurements of the color quantification of smart indicator labels, TPC measurements, TVBN, $\mathrm{pH}$, and the measurement of the level of correlation between the color indicator labels against all parameters of the fish rot test.

\subsection{Data Analysis}

Data from the results of color measurement analysis were displayed in graphical and ${ }^{\circ}$ Hue diagrams. TPC, TVBN, and PH measurement data were displayed in the diagram. Besides, the correlation between the color indicator label and all the parameters of fish rot were presented in one graph using the Sigma Plot software version 14.0.

\section{Results and Discussion}

\subsection{The Color Change Response of Smart Indicator Label}

The results showed that the smart indicator label applied to Tuna fillets experienced a color change during storage. The color change of smart indicator could be seen in Figures 3 , 4,5 , and 6 . 


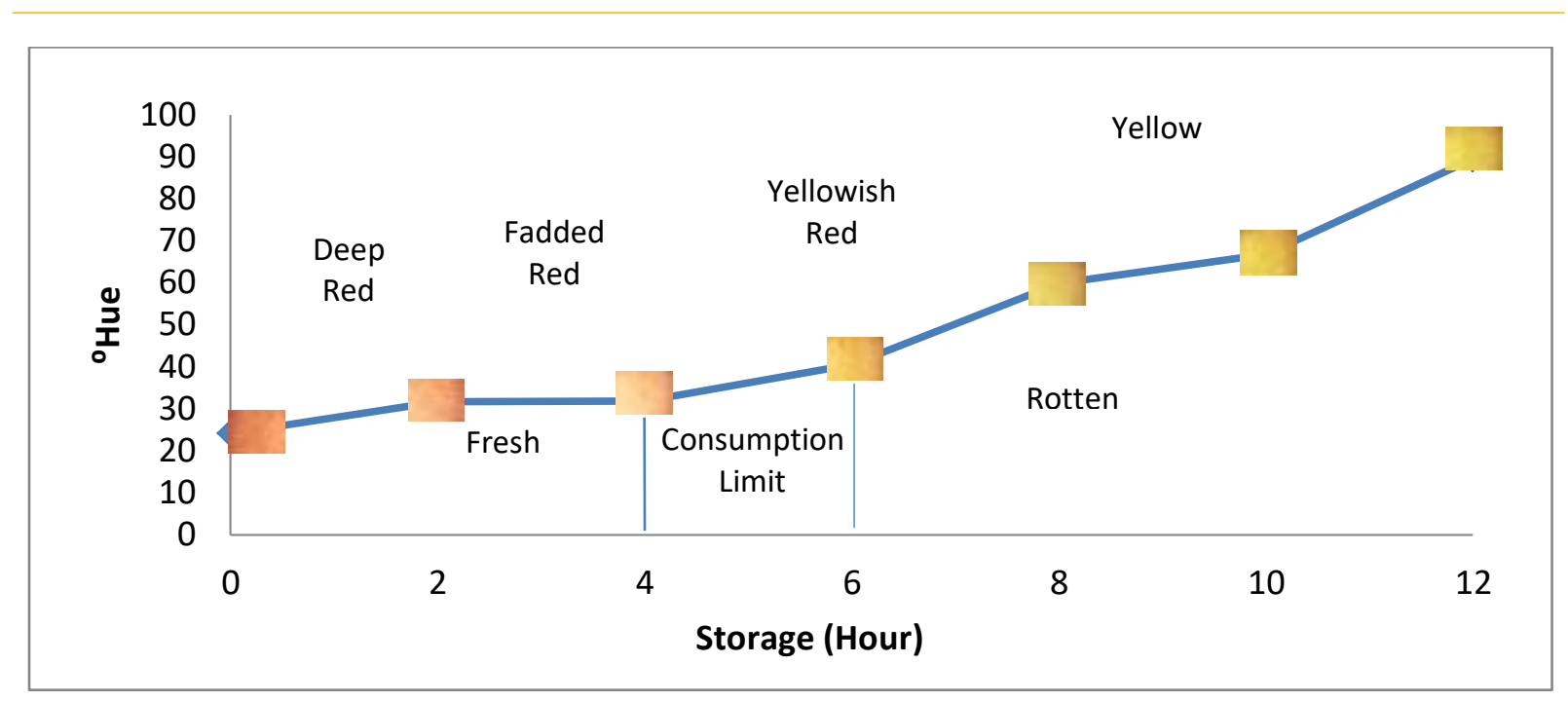

Figure 3. Without Garlic Extract Addition (0\%).

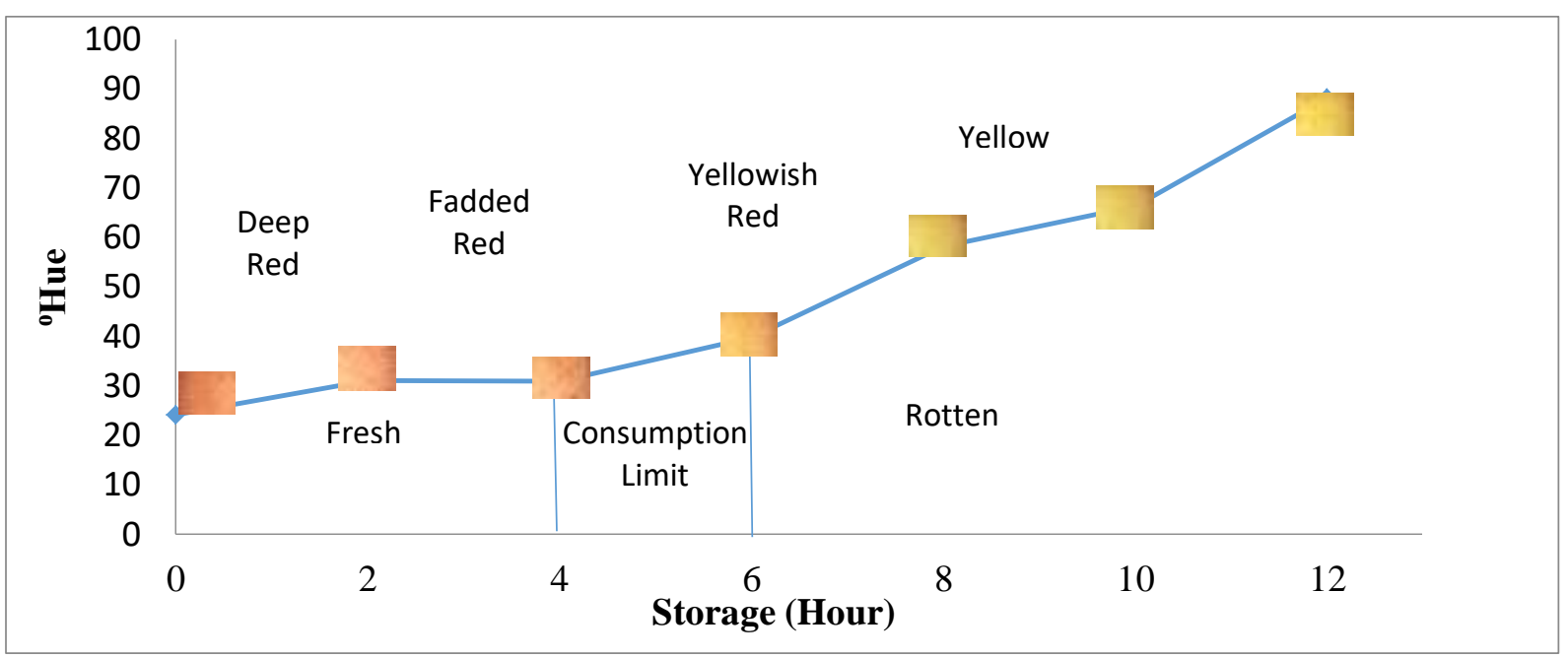

Figure 4. Addition of Garlic Extract 5\%.

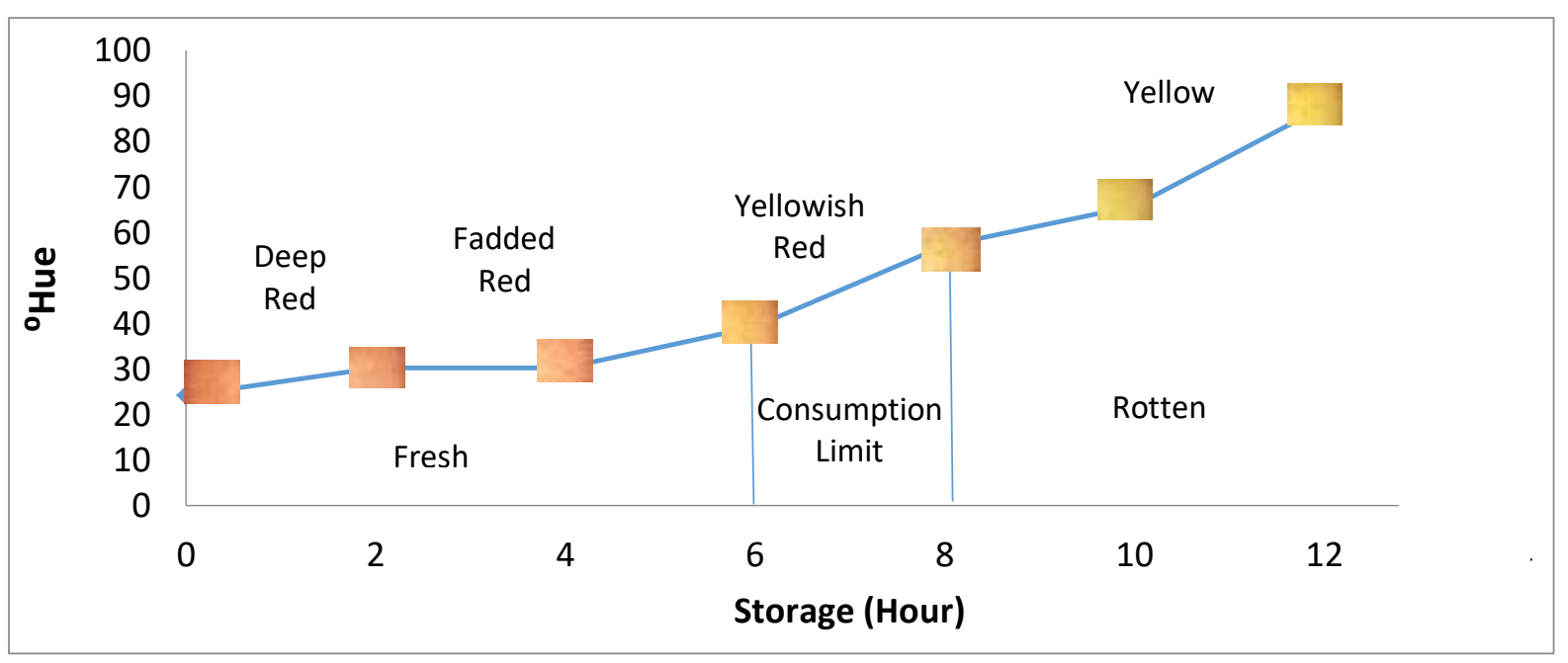

Figure 5. Addition of Garlic Extract 10\%. 


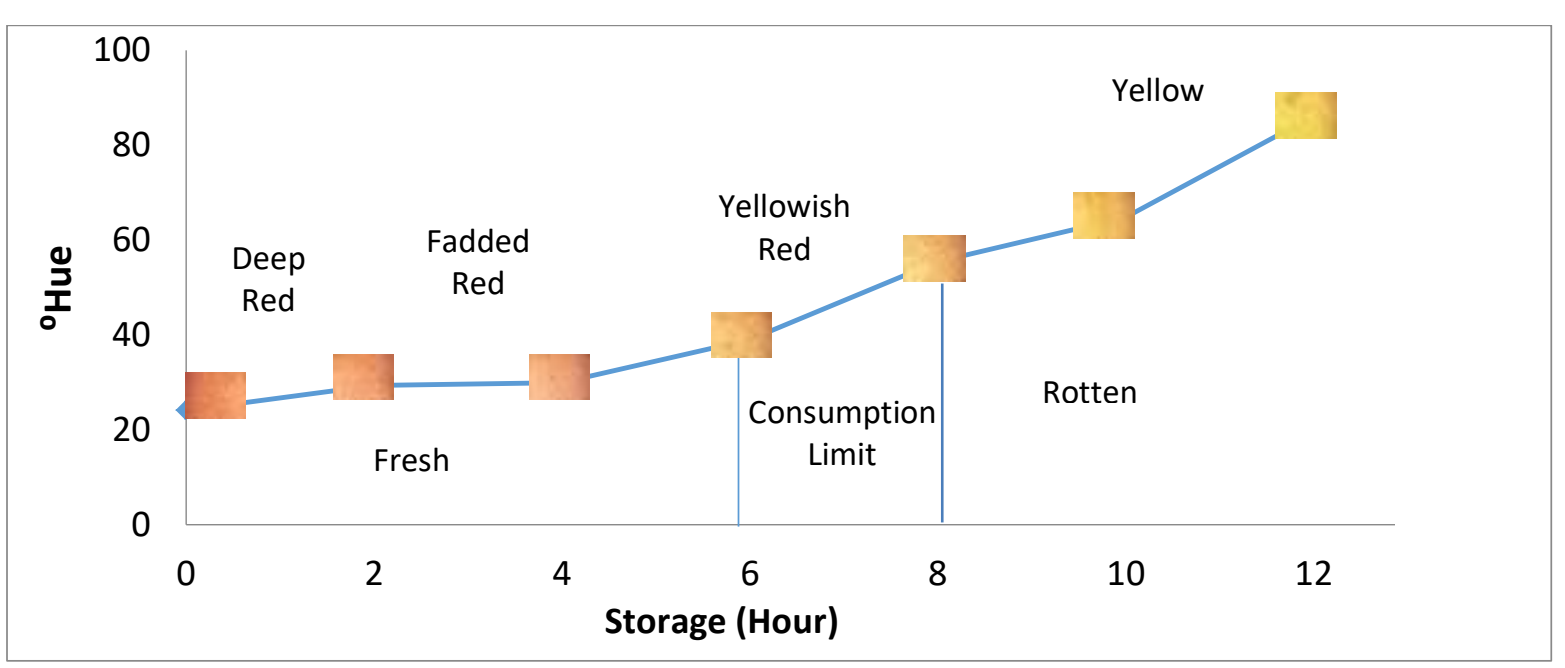

Figure 6. Addition of Garlic Extract 15\%.

A color score of ${ }^{\circ}$ Hue could be used to see the overall color change on the label from the beginning until the label changes. The score of ${ }^{\circ}$ Hue could be determined from the calculation of the inverse tangent comparison of the $b$ and the values of the colorimeter. The graph of ${ }^{\circ}$ Hue value on the color change of the smart indicator label could be seen in Figure 7.

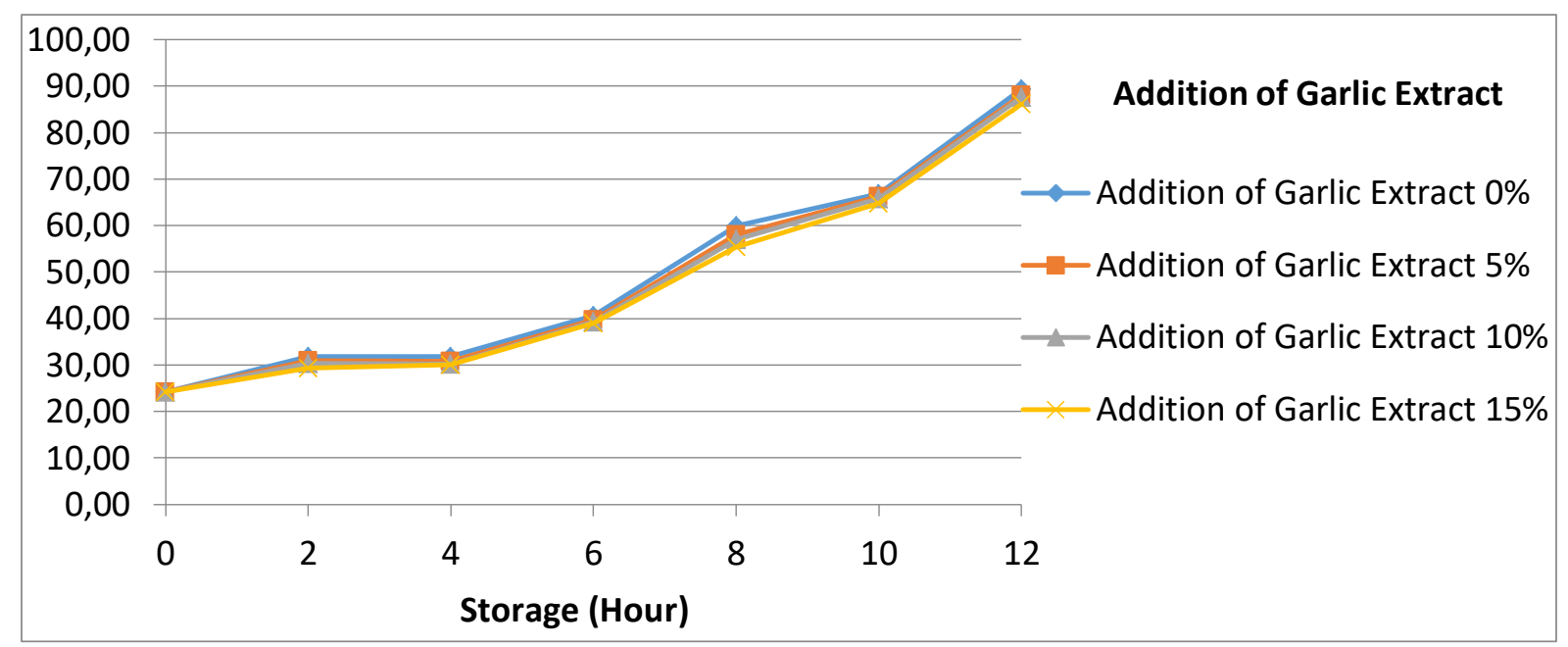

Figure 7. ${ }^{\circ}$ Hue Value of Smart Indicator Label During Storage.

Based on the graph, it appeared that the value of ${ }^{\circ} \mathrm{Hue}$ on the smart indicator label had increased during storage. An increase in the value of ${ }^{\circ} \mathrm{Hue}$ was due to the smart indicator label that had experienced changes in color from deep red to yellow. The change occurred as a result of the response to the quality conditions of packaged Tuna fillets. Color changes could also be illustrated with diagrams of ${ }^{\circ}$ Hue. 


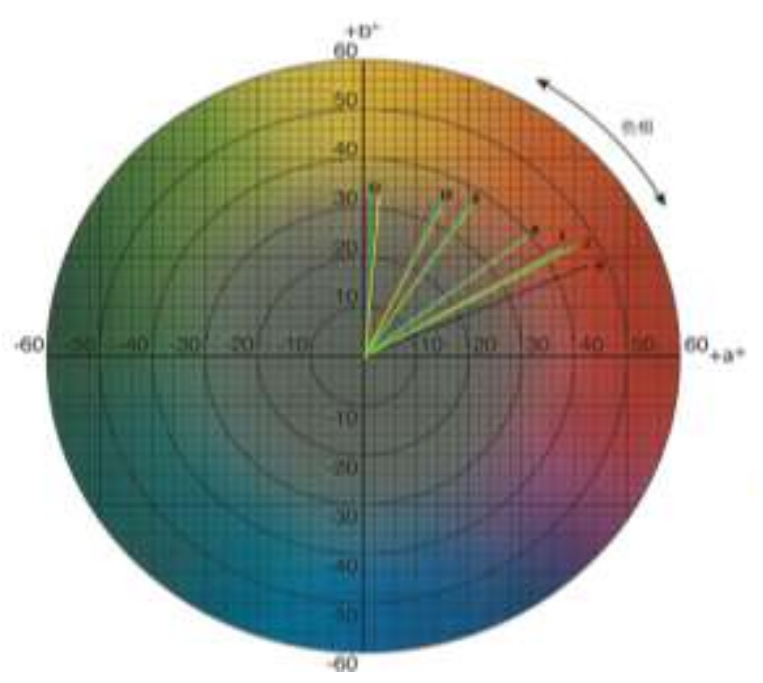

Information:

- = Garlic Extract $0 \%$

- = Garic Extract $5 \%$

- = Garlic Extract 10\%

$=$ Garlic Extract $15 \%$

\section{Figure 8. ${ }^{\circ}$ Hue Diagram.}

Based on the ${ }^{\circ}$ Hue diagram, it could be seen that the color of the smart indicator label during storage experiences movement from quadrant I (solid red) to diagram II (yellow).

An increase in value ${ }^{\circ}$ Hue was closely related to an increase in total volatile nitrogen bases (TVBN) during storage as a result of the decomposition of fish nutrient components by enzymes and microbes. These volatile bases would be accumulated in the package so that there was an increase in $\mathrm{pH}$ in the packaging system, which was then detected by the indicator so that the smart indicator label changed color from deep red to yellow. According to Ramadhani (2016), the color change mechanism of the smart indicator label started from the volatile component of ammonia $\left(\mathrm{NH}_{3}\right)$ would react with $\mathrm{H}_{2} \mathrm{O}$ from the evaporation results when the fish was stored, so that it would produce $\mathrm{NH}_{4}{ }^{+}$and $\mathrm{OH}^{-}$which would be released and captured by the indicator. Therefore, the smart indicator label would turn yellow when the fish had been damaged (8).

\subsection{The Analysis Results of Fish Microbial Total Value (TPC Method)}

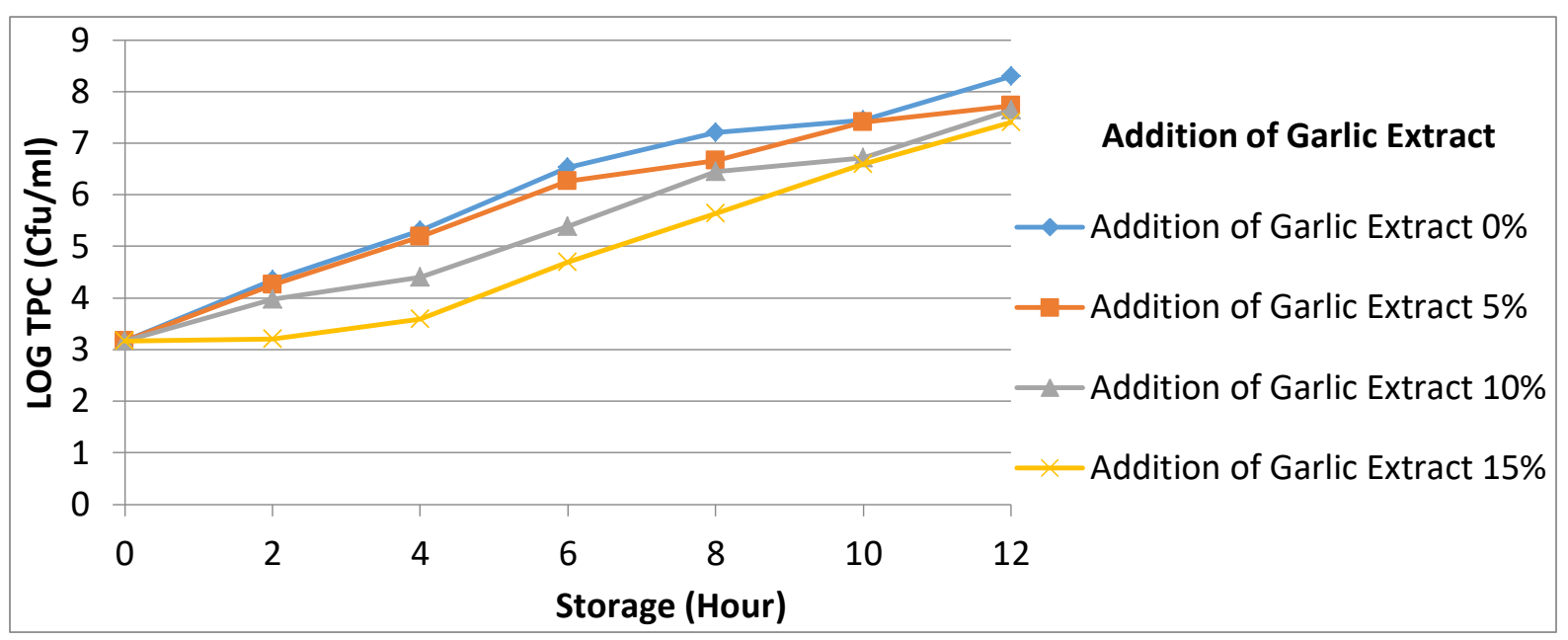

Figure 9. TPC Value of Fillet Tuna During Storage. 
Based on the freshness quality standards of fish set by Indonesian National Standard (SNI) (2006), the limit on the number of TPC microbes in fish is $5 \times 10^{5} \mathrm{Cfu} / \mathrm{g}$. The results of this study indicated that Tuna fillets no longer met the criteria at the 6th-hour storage for the use of garlic extract concentration of $0 \%$ and $5 \%$, the 8th-hour storage for the use of $10 \%$ concentration of garlic extract and the 10th-hour storage for the use of garlic extract concentration of $15 \%$. Variance test results showed that there were significant differences in the addition of garlic extract with different concentrations to the increase in TPC values, with a significance value $(p<0.05)$.

\subsection{Analysis of Fish pH Value}

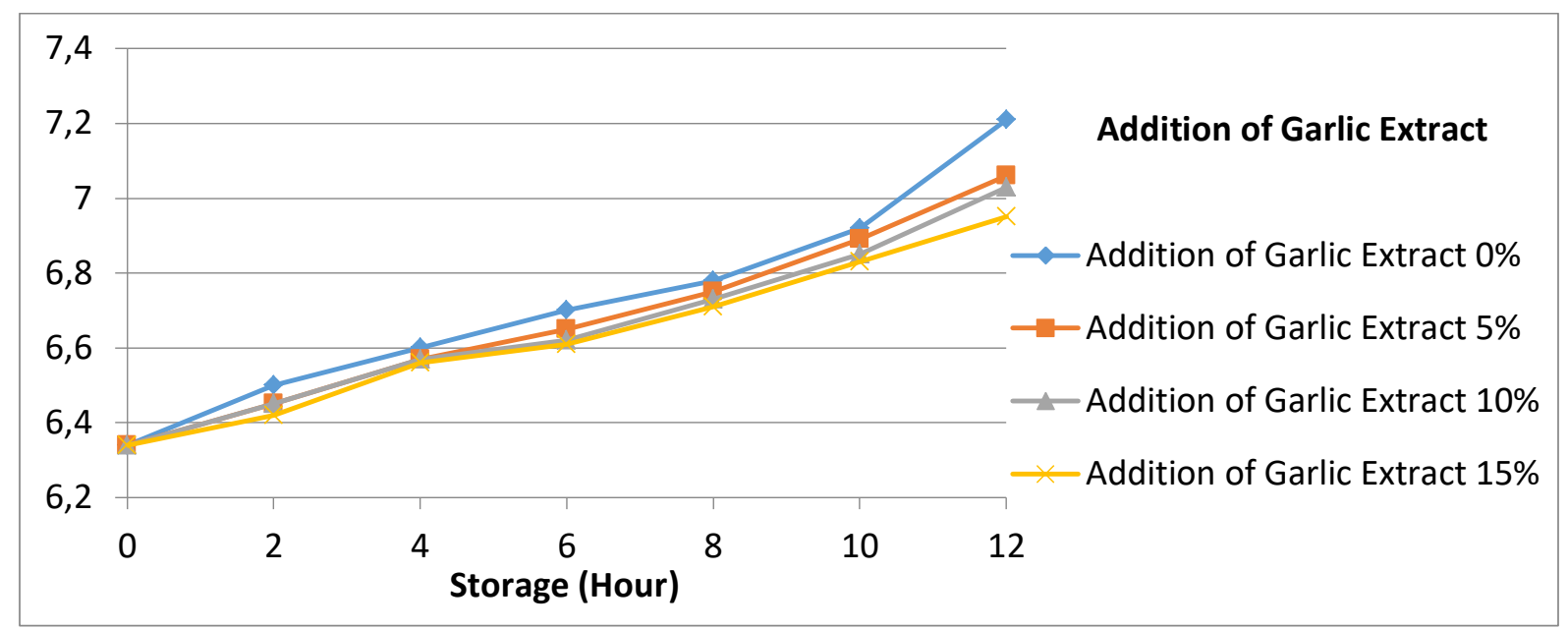

Figure 10. pH Value of Tuna Fish Fillet During Storage.

Based on the results obtained, indicated that an increase in $\mathrm{pH}$ value in fish fillets during storage. Variance test results showed that there were significant differences in the addition of garlic extract with different concentrations to increase the $\mathrm{pH}$ value, with a significance value $(p<0.05)$.

\subsection{The Analysis Results of Volatile Bases Nitrogen Total Value (TVBN) on Tuna Fillets}

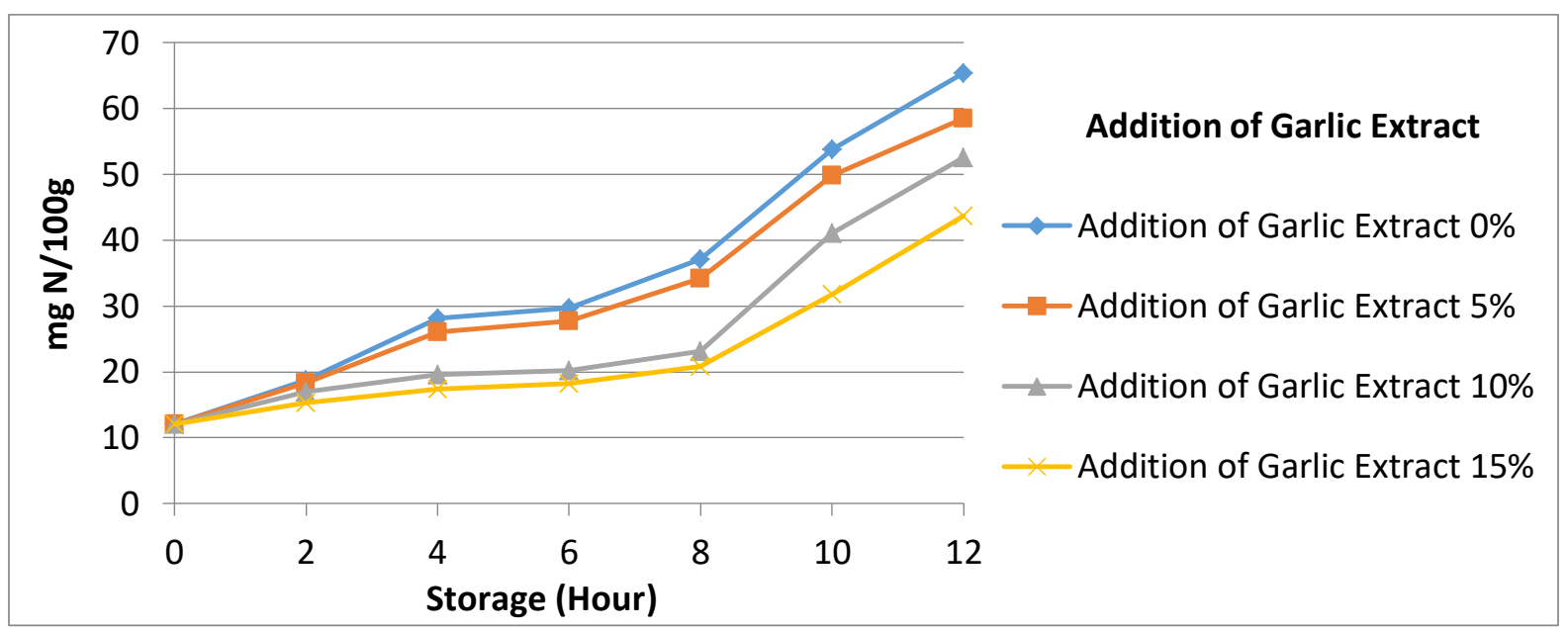

Figure 11. TVBN Value of Tuna Fish Fillets During Storage. 
Based on the results showed that the TVBN value of fish fillet had increased during storage. Based on the freshness quality standard of the fish put forward by Ramadhani (2016) the initial TVBN value of fresh Tuna before storage was $12.05 \mathrm{mg} \mathrm{N} / 100 \mathrm{~g}$ included in the fresh quality category. TVBN value showed that the quality of the fish had rotten at the 8th hour with the concentration addition of garlic extract $0 \%$ and $5 \%$ and at the 10 th hour with the concentration addition of garlic extract $10 \%$ and $15 \%$. Variance test results showed that there were significant differences in the addition of garlic extract with different concentrations against to the increase of TVBN value, with a significance value $(p<0.05)$.

\subsection{The Level of Correlation Between Smart Indicator Label Sensor Responses and Various Fish Quality Deterioration Parameters}

Correlation of the color change of the smart indicator label with all parameters of Tuna fillet rot with the addition of garlic extract with different concentrations is presented in figures $12,13,14$, and 15.

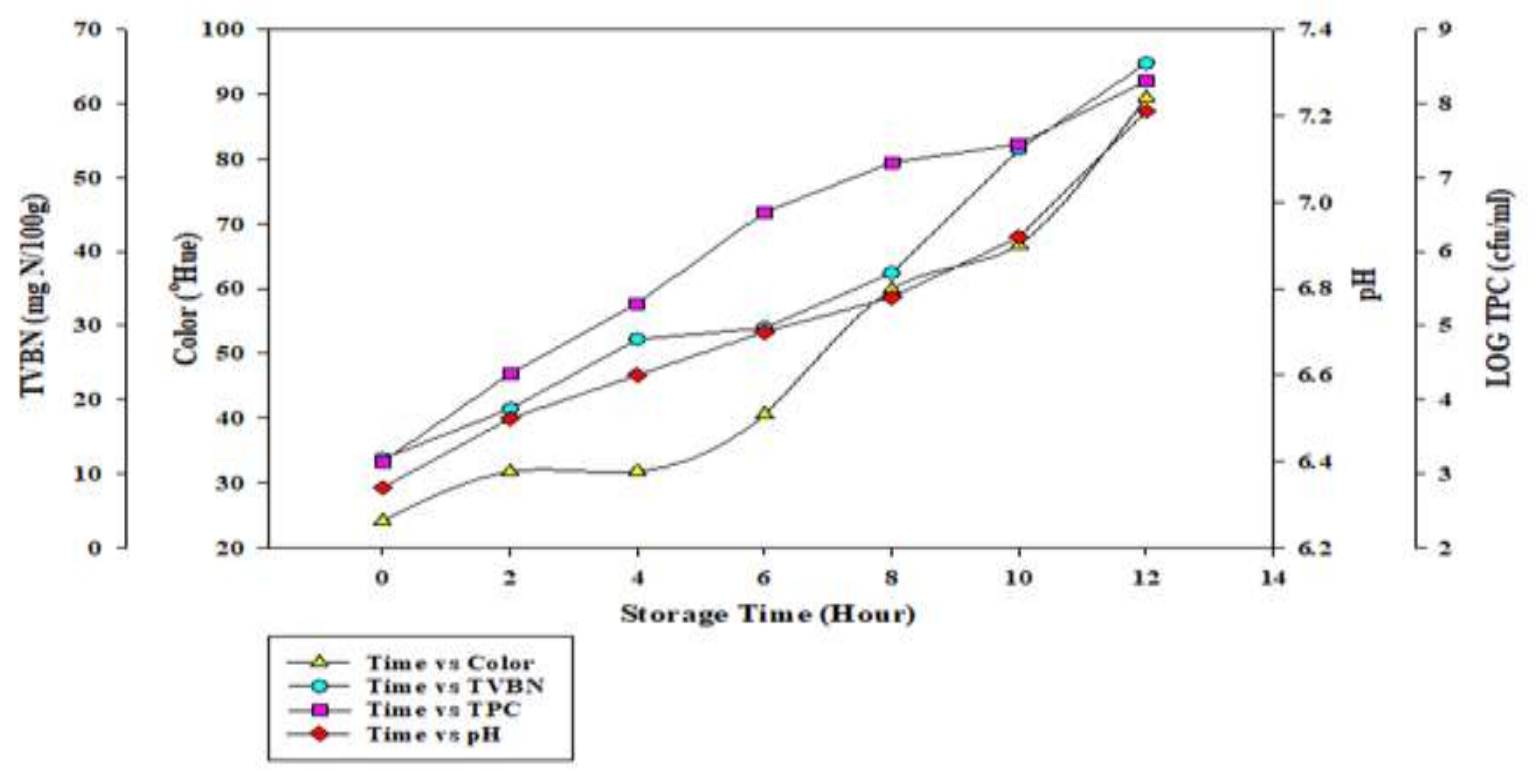

Figure 12. Without Addition of Garlic Extract (0\%). 


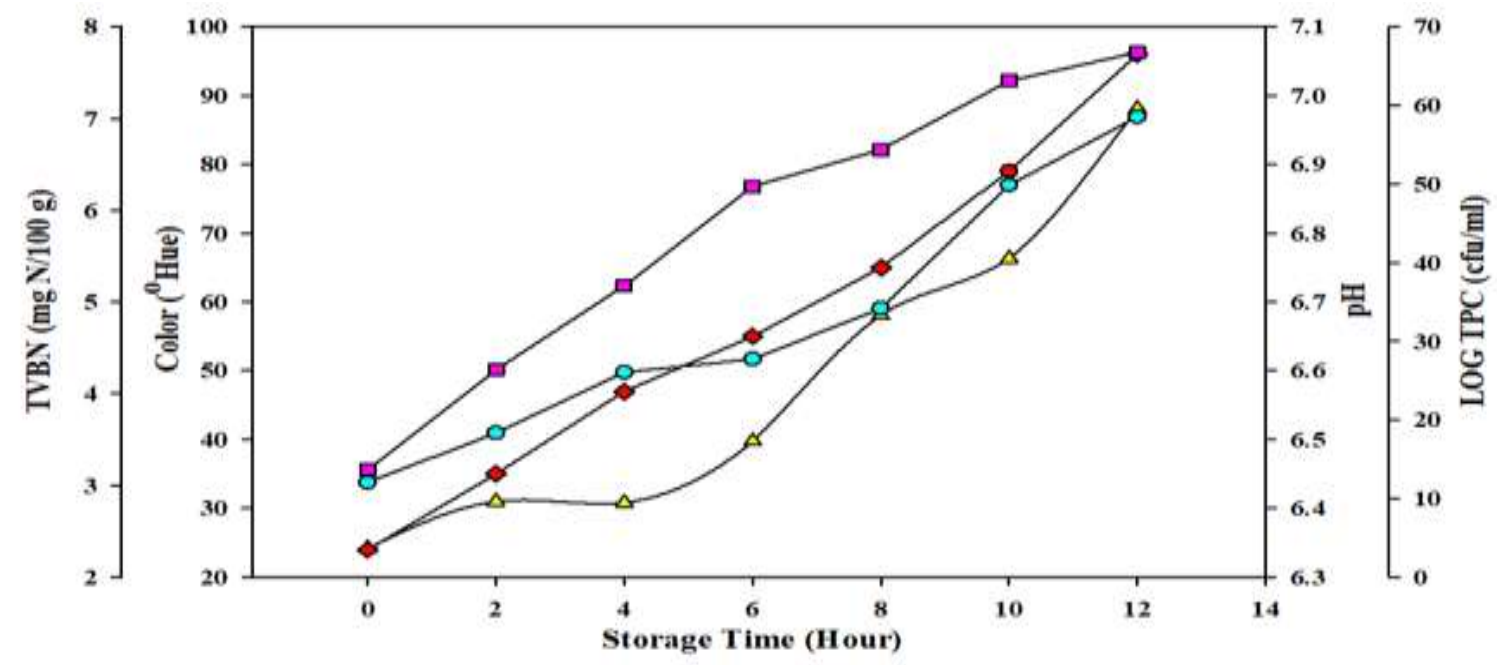

$\triangle$ Time vs Color

- Time vs TVBN

- Time vs TPC
- Time vs pH

Figure 13. Addition of Garlic Extract (5\%).

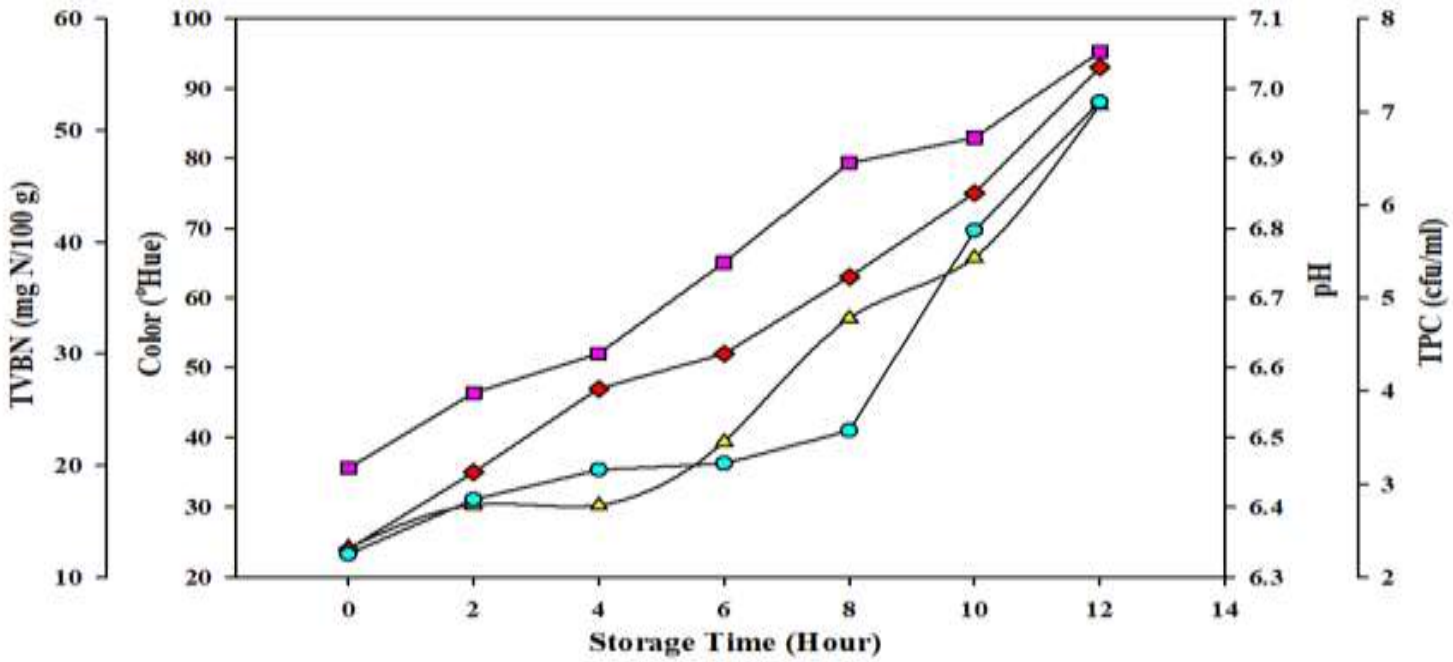

$$
\begin{aligned}
& -\triangle \text { Time vs Color } \\
& -0 \text { - Time vs TVBN } \\
& - \text { Time vs TPC } \\
& - \text { Time vs pH }
\end{aligned}
$$

Figure 14. Addition of Garlic Extract (10\%). 


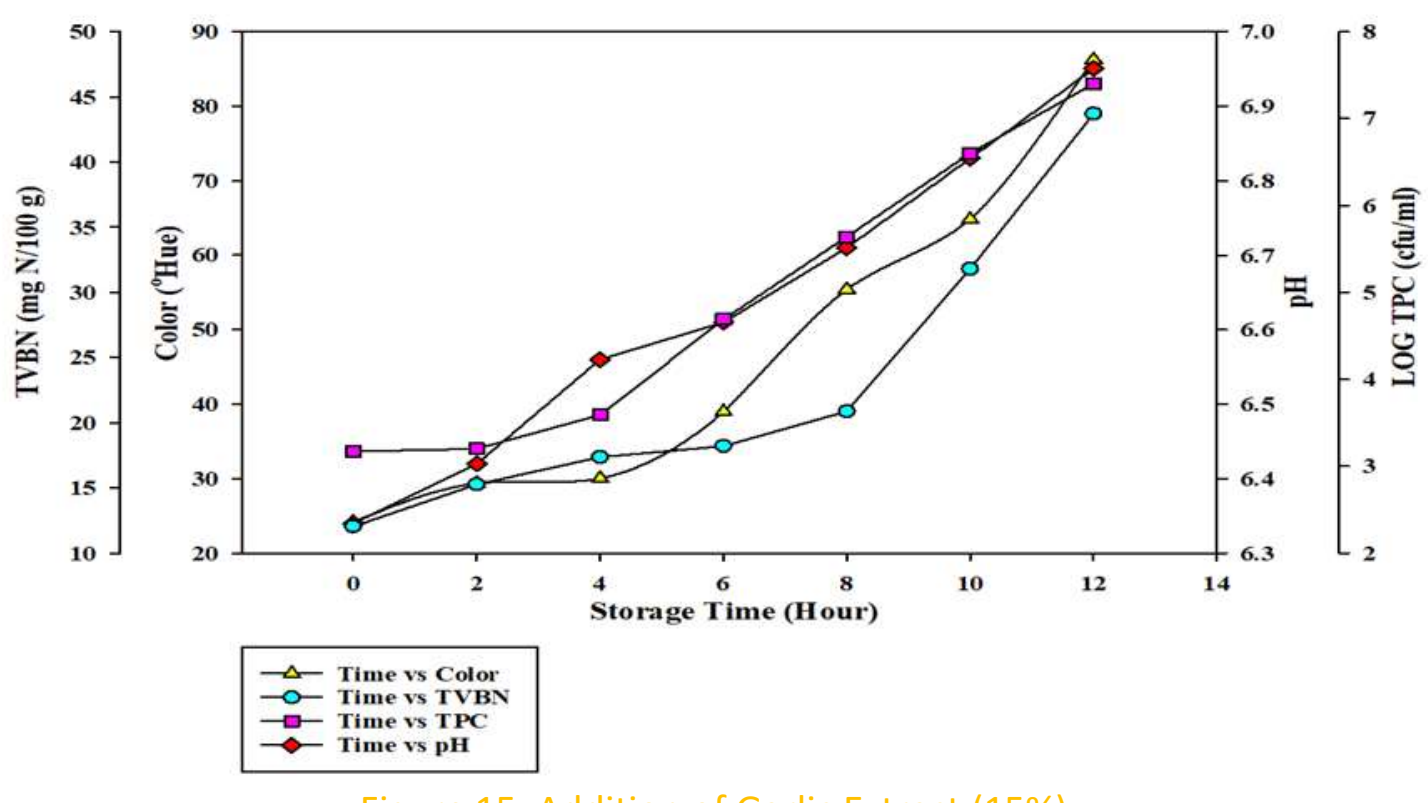

Figure 15. Addition of Garlic Extract (15\%).

Figure 12, 13, 14, and 15 showed that the increase in the value of TPC, TVBN, and pH was in line with the increase of the color change of smart indicator label that changed from deep red to yellow which indicated that the Tuna fillet had been rotten. An increase in all parameters of fish fillet rot and the color label indicator analysis during storage was closely related to the role of enzymes and microbes in decomposing fish nutrients after the fish died. In this study, the treatment used was the storage of Tuna fillets at room temperature. Tuna is a food that has nutrition and high water content, in addition to the storage temperature used was the room temperature, which is the optimum temperature for microbial growth of spoiled fish so that these conditions were in accordance with the microbial growth environment. With the increase in microbes, the decomposed nutrient component also increased, which caused the $\mathrm{pH}$ of fish during storage also increased. The increase in $\mathrm{pH}$ in fish was in line with the increasingly volatile bases produced. These volatile base compounds would accumulate in the packaging system, which was then detected by the indicator, so that an intelligent indicator labels change color.

The difference in the increase in the value of TPC, TVBN, $\mathrm{pH}$ of fish, and the color of the indicator label during storage was caused by the addition of garlic extract with different concentrations. Garlic extract has an allicin compound, which is a bioactive compound that is volatile so that when applied to Tuna fillets, these compounds would evaporate and diffuse throughout the surface of the fish fillet so that it could inhibit the growth of microbes. This was in accordance with Prihandani (2015) that garlic had a bioactive substance in the form of allicin, which was volatile (9). Then complemented by Iriani (2014) that the bioactive substances in the active packaging would be released during storage to the surface of food through evaporation or diffusion so that it could inhibit the growth of microbes (10).

Garlic, as a producer of antimicrobial compounds, was described by Ankri's research (1999), which stated that allicin had a broad spectrum, including strains of Escherichia coli, Candida albicans (fungi) and protozoan parasites (11). Besides, according to Ichsan (2009), allicin also had a broad spectrum of antibiotics against gram-positive and gram-negative 
bacteria such as penicillin (12). Muslim et al. (2009) also added that allicin in garlic had a high permeability in penetrating bacterial cell walls by destroying the sulfhydryl groups that made up the bacterial cell membrane so that the structure of the bacterial cell wall was damaged. Its growth was inhibited (13). This was also supported by Wiryawan (2005), which stated that the higher of the garlic extract concentration, the higher the antibacterial activity (14). This was what causes fish fillets with the use of $15 \%$ garlic extract concentration had a longer increase in TPC, TVBN, $\mathrm{pH}$, and color labels compared to the addition of garlic extract concentrations of $10 \%, 5 \%$, and $0 \%$.

The pattern of relationship between the deterioration parameters of the fish quality with the analysis value of the indicator label color was also in line with Pacquit et al., (2006) who also got the same pattern of relating to the increase in the TPC value of cod and was linear with the sensor color change from the cellulose-acetate film (15). Visually, the smart indicator label with the basic ingredients of Whatman paper number 1 and the MR + BTB indicator (1:1) $\mathrm{pH} 2.55$ produced in this study had a change in color from deep red (initial) to yellow (end of observation) when used directly in detecting rot Tuna.

\section{Conclusions}

Based on the results obtained, it could be concluded that first, visually, the profile of the color change of the smart indicator combination of MR + BTB, namely from deep red to faded red, then to yellowish-red (orange) and finally yellow when the fish fillet had decayed. Second, the active paper with the addition of garlic extract concentration of $15 \%$ had the best effectiveness in minimizing the occurrence of quality degradation in Tuna fillets during storage, which was then followed by concentrations of $10 \%, 5 \%$, and $0 \%$. The effectiveness could be seen from the increase in smaller values of all fish rot parameters compared to the addition of garlic extract with lower concentrations. Third, the degree of correlation between the value of intelligent indicator color analysis on various parameters of the fish rot test showed a positive correlation, which showed a similar trend pattern in detecting the level of Tuna rot.

\section{References}

1. Fisheries S of the IM of MA and. Export of Tuna / Tuna by Major Destination Countries, 2002-2015. 2015;

2. Lu F, Ding Y, Ye X, Liu D. Cinnamon and nisin in alginate-calcium coating maintain quality of fresh northern snakehead fish fillets. LWT-Food Sci Technol. 2010;43(9):1331-5.

3. Kuswandi B, Nurfawaidi A. On-package dual sensors label based on $\mathrm{pH}$ indicators for real-time monitoring of beef freshness. Food Control. 2017;

4. Kuswandi B, Maryska C, Jayus, Abdullah A, Heng LY. Real time on-package freshness indicator for guavas packaging. J Food Meas Charact. 2013;7(1):29-39.

5. Karina R. Effect of Garlic Extract (Allium sativum) Against Streptococcus mutans Bacteria Growth In Vitro. Bogor Agricultural University; 2013.

6. Hidayat sh, Syarifuddin A, Dirpan A. Analysis of the effectiveness of active paper use by adding garlic extract in inhibiting bacterial growth. IOP Conf Ser Earth Environ Sci. 2020;575:1-4.

7. Khasanah L., Atmaka W, Kurniasari D, Kawiji K, Utami R. Characterization of Active Paper Packaging With the Addition of Oleoresin Pulverizer in Lemongrass Kitchen 
(Cymbopogon Citratus). 2017;37(1):59-68.

8. Ramadhani K. Intelligent Label Detection of Fish Freshness Based on Bromocresol Purple Color Indicator. Bogor (ID): Bogor Agricultural University; 2016.

9. Prihandani S. Antibacterial Power Test of Garlic (Allium Sativum L.) Against Staphylococcus Aureus, Escherichia Coli, Salmonella Typhimurium And Pseudomonas Aeruginosa In Improving Food Safety. Inform Pertan. 2015;24:63.

10. Iriani ES, Widayanti SM, Miskiyah, Juniawati. The Effect of Encapsulated Garlic Extract Against Antimicrobial Packaging Characteristics. J Chem Packag. 2014;36(2):1-6.

11. Ankri S, Mirelman D. Antimicrobial properties of allicin from garlic. Microbes Infect. 1999;1(2):125-9.

12. Ichsan, B Z. Antibacterial Effects of Garlic Extract (Allium Sativum) Against Streptococcus Mutans Growth In Vitro. Surakarta Sebelas Maret University; 2009.

13. Muslim, Holty M., Widjajanti H. Use of Garlic Extract (Allium Sativum) to Treat Siamese Patin Fish (Pangasius Hypophthalmus) Infected by Aeromonas Hydrophylla Bacteria. Indones Aquac J. 2009;8(1):91-100.

14. Wiryawan KG, Suharti S, Bintang M. Antibacterial Study of Ginger, Ginger and Garlic on Salmonella typhimurium and the Effect of Garlic on the Performance and Response of Broilers. Anim Husb Media. 2005;28(2):52-62.

15. Pacquit A, Lau KT, McLaughlin H, Frisby J, Quilty B, Diamond D. Development of a volatile amine sensor for the monitoring of fish spoilage. Talanta. 2006;69(2):515-20. 